\title{
Hábitos bucais deletérios e suas consequências em Odontopediatria
}

\author{
Deleterious oral habits and its consequences in Pediatric Dentistry
}

\author{
Thays Ferreira Gisfrede \\ Cirurgiã-dentista \\ Juliana Sayuri Kimura \\ Mestre em Ciências Odontológicas, Área de Concentração em Odontopediatria \\ Professora da Clínica Integrada Infantil da Uniararas \\ Alessandra Reyes \\ Doutora em Ciências Odontológicas, Área de Concentração em Odontopediatria \\ Professora da Clínica Integrada Infantil da Uniararas \\ Júlio Bassi \\ Mestre em Odontopediatria \\ Professor da Clínica Integrada Infantil da Uniararas \\ Rayen Drugowick \\ Doutora em Saúde da Criança e Adolescente \\ Professora da Clínica Integrada Infantil da Uniararas

\section{Ronilza Matos} \\ Doutora em Ciências Odontológicas, Área de Concentração em Odontopediatria \\ Professora da Clínica Integrada Infantil da Uniararas \\ Tamara Kerber Tedesco \\ Doutora em Ciências Odontológicas, Área de Concentração em Odontopediatria \\ Professora da Clínica Integrada Infantil da Uniararas
}

- Os autores declaram que não há conflito de interesse.

\section{Resumo}

Objetivo: $\mathrm{O}$ objetivo deste trabalho foi revisar a literatura vigente sobre os hábitos bucais deletérios e suas consequências em Odontopediatria. Material e Métodos: Para isso, foi realizada uma busca nas bases de dados Bireme e Pubmed/MEDLINE, utilizando como palavras-chave: sistema estomatognático, hábitos bucais e Odontopediatria. Resultados: Pode-se observar que os hábitos bucais (nutritivos e não nutritivos) encontram-se diretamente relacionados com as funções do sistema estomatognático, acarretando em inadequações no posicionamento dos maxilares, lábios, língua e palato, alterações no desenvolvimento e posição dos dentes, problemas de fala e na respiração e alterações nos movimentos necessários para mastigar e deglutir os alimentos. Conclusão: Conclui-se que é de extrema importância um diagnóstico precoce e um trabalho multidisciplinar para uma possível remoção do hábito bucal deletério e suas consequências.

Palavras-chave: sistema estomatognático; hábitos orais; Odontopediatria.

\section{ABSTRACT}

Objective: The aim of this study was to review the current literature about the deleterious oral habits and their consequences in Pediatric Dentistry. Material and Methods: For that, a search was performed in the Bireme and Pubmed/MEDLINE databases, using the keywords: stomatognathic system, oral habit and pediatric dentistry. Results: It was observed that oral habits (nutritious and non-nutritious) are directly related to the functions of stomatognathic system, causing consequences such as inadequacy in the positioning of the jaws, lips, tongue and palate, changes in development and position of teeth, speech problems and breathing and changes in the necessary movements to chew and swallow food. Conclusion: It can be concluded that is extremely important an early diagnosis and multidisciplinary work for possible removal of deleterious oral habits and their consequences.

Keywords: stomatognathic system; oral habits; Pediatric Dentistry.

\section{Introdução}

s hábitos, os quais são ditos como automatismos adquiridos, realizados com frequência e inconscientemente, quando relacionados com a cavidade bucal de forma deletéria, podem resultar em alterações tanto nos tecidos musculares, como dentários e ósseos, mostrando prevalência de até $76 \%$ em ambos os sexos. ${ }^{1-3}$ Esses hábitos podem alterar o padrão de crescimento normal e danificar a oclusão, determinando forças musculares desequilibradas que, durante o crescimento, distorcem a forma da arcada dentária e alteram a morfologia normal. ${ }^{4}$

Desta forma, pode-se afirmar que esses hábitos são um dos fatores etiológicos das más oclusões, ${ }^{5}$ as quais apresentam impacto na qualidade de vida e felicidade de crianças em fase escolar. ${ }^{6}$ Devemos destacar que existem hábitos bucais considerados normais, como sucção nutritiva, mastigação, deglutição e respiração, e aqueles deletérios, como sucção não nutritiva, hábitos de morder e funcionais. O desequilíbrio causado no sistema estomatognático, depende da frequência, duração e intensidade desses hábito.,

Quando há a presença do hábito bucal deletério até os três anos de idade, há chance de ocorrer a autocorreção, de possíveis desarmonias oclusais. No entanto, quando não removido o hábito, a criança pode apresentar alterações orofaciais, comprometendo seu crescimento facial. ${ }^{8,9}$ Desta forma, o objetivo deste trabalho foi revisar a literatura vigente sobre os hábitos bucais deletérios e suas consequências em Odontopediatria, para a eliminação precoce desses hábitos, como forma de prevenir e diminuir consequências futuras. 


\section{Material e Métodos}

A seleção de artigos foi realizada por meio de uma busca nas bases de dados Bireme e Pubmed/MEDLINE, utilizando como palavras-chave: sistema estomatognático, hábitos bucais e Odontopediatria. Foram considerados elegíveis os artigos que relatavam a influência dos hábitos bucais em Odontopediatria. Não houve restrição nos anos de publicação e nem em idioma para inclusão dos artigos.

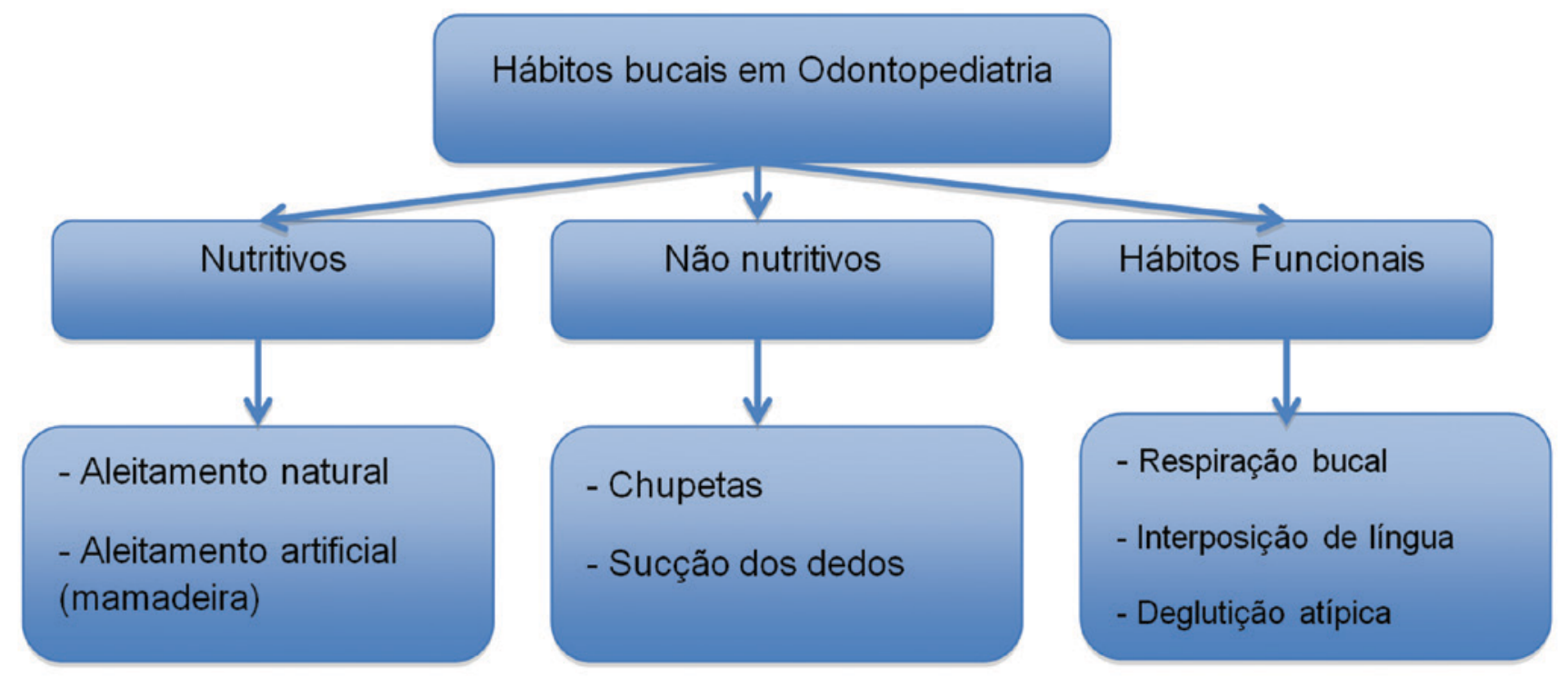

Figura 1. Classificações dos hábitos bucais observados em Odontopediatria

\section{Revisão de Literatura}

\section{- Definição}

Os hábitos bucais deletérios alteram o padrão de crescimento normal e danificam a oclusão, determinando forças musculares desequilibradas que, durante o crescimento, distorcem a forma da arcada dentária e alteram a morfologia normal. ${ }^{4}$ O hábito irá se instalar pelo fato de ser agradável e proporcionar satisfação à criança. No seu início, o hábito será consciente, porém, gradativamente, por conta do ato de repetição, este hábito se tornará inconsciente. ${ }^{10}$

A partir da $29^{a}$ semana de vida intrauterina, através de ultrassonografia, podemos observar o processo de sucção, no entanto ela só estará perfeitamente madura na $32^{\mathrm{a}}$ semana. Após o $5^{\circ}$ mês de vida, a maior parte dos bebês tem início do ciclo de relação entre boca, mãos e olhos, sendo que a boca torna-se um processo de descobertas e investigações para os bebês, podendo ser um meio para a instalação de um hábito bucal..11,12

\section{- Classificação e Etiologia}

Os hábitos bucais deletérios podem ser divididos em: sucção não nutritiva (uso de chupetas e succionar os dedos); sucção nutritiva (sucção do seio materno; sucção da mamadeira sendo ela aleitamento artificial) e hábitos funcionais (respiração bucal, deglutição atípica) (Figura 1). ${ }^{5}$

Alguns fatores vêm sendo relatados como possíveis fatores etiológicos de hábitos bucais deletérios. A manutenção da sucção, após a fase reflexa, pode ser decorrente de problemas psicológicos, ambientais (ciúmes, necessidade de atenção) e, até mesmo, distúrbio alimentar. Além disso, o período e a forma de aleitamento no bebê também parecem estar relacionados, uma vez que crianças que recebem o aleitamento materno (sucção do peito) tem menor chance de desenvolverem hábitos bucais deletérios. ${ }^{5}$

Quando a criança desenvolve um hábito, o acarretamento das alterações morfológicas irá depender de três fatores: frequência, intensidade e duração desse hábito (Tríade de Graber), assim como a tendência individual de cada criança que está relacionada ao tipo de crescimento facial. ${ }^{7}$

\section{- Aleitamento Materno}

A Organização Mundial de Saúde recomenda o aleitamento materno exclusivo durante os primeiros seis meses e a manutenção do aleitamento materno complementar até os dois anos de vida da criança. De acordo com Neiva et al. ${ }^{13}$, nos primeiros meses de vida da criança é importante que ela receba o aleitamento por sucção do seio materno e não pela mamadeira, pois a sucção no seio materno aumenta a possibilidade desta criança ser um respirador predominantemente nasal ao longo da vida. A literatura aponta para três diferenças entre a sucção natural (aleitamento materno) e a sucção artificial 
(mamadeira) que necessitam de maior atenção, sendo elas: pega (posicionamento da língua e deglutição), a forma que o leite será extraído e a forma e elasticidade que são presentes nos bicos. ${ }^{14}$

Quando o bebê faz movimentos de protrusão e retrusão da mandíbula durante a extração do leite ele propicia um correto crescimento e desenvolvimento orofacial e mandibular. A maior importância da amamentação para o bebê é a formação de uma correta relação maxilo-mandibular, que estimula as articulações temporomandibulares, deixando a estrutura articular preparada para receber alimentos sólidos. ${ }^{14}$

Os principais fatores que determinam a paralisação da sucção natural são: hábito de sucção de chupeta, idade da mãe, conselho dos avós para uso de outros meios de sucção e baixa escolaridade. ${ }^{15}$ Segundo Barreto et al. ${ }^{16}$ crianças que foram aleitadas pelo seio materno têm maior chance de não desenvolverem hábitos deletérios, pois, acontece um trabalho muscular intensificado, fazendo com que os músculos peribucais fiquem cansados, resultando no cansaço do bebê, fazendo com que ele não busque outras alternativas de sucção, como por exemplo, uso de chupetas dentre outros objetos.

\section{- Aleitamento Artificial - Mamadeira}

A alternativa mais fácil para a interrupção do aleitamento natural seria o aleitamento artificial com o uso de mamadeiras, pois ela iria saciar as necessidades do bebê e acalmar a ansiedade presente nos pais, solucionando os problemas de imediato. ${ }^{14}$ Com os avanços na tecnologia o aleitamento através da mamadeira se tornou mais prático. Além do uso da mamadeira, outros preceitos contribuem para a distância mãe-filho, como exemplo a babá ou a cuidadora, pois é ela quem se encarrega de cuidar do bebê tanto na alimentação quanto em todos os outros cuidados. ${ }^{17}$

Várias são as causas e alterações que podem ocorrer por conta do uso de mamadeira, sendo que umas das alterações são das funções de mastigação, sucção e deglutição, podendo causar má oclusão dentária. As crianças que apresentam sucção mista (tanto de seio como na mamadeira) têm maior chance de desenvolver uma maneira inadequada de sucção do seio materno. ${ }^{15}$

Quando a sucção é feita com mamadeira, a criança recebe uma pequena quantidade de estimulação motora-oral, acarretando várias consequências sendo elas: flacidez dos músculos perioral e da língua, gerando uma instabilidade na deglutição, deformidade dos dentes e da face, gerando uma mordida aberta anterior ou lateral e disfunções respiratórias. ${ }^{13}$ Segundo Vinha et al. ${ }^{14}$, a criança demora em média de 5 a 10 minutos para fazer todo o processo de sucção da mamadeira, sendo que esse tempo não é suficiente para suprir todas as necessidades fisiológicas e neurológicas de suç̧ão da criança, não podendo portanto substituir o aleitamento materno por essas opções.

Além dos desiquilíbrios no crescimento que levam a disfunções oclusais, o uso de mamadeira pode levar ainda à doença cárie que, quando acomete crianças de até 3 anos e 11 meses e que se observa que seu principal fator etiológico está relacionado ao uso de mamadeira noturno, pode ser chama de cárie de acometimento precoce da infância. ${ }^{18}$

Nos casos em que a mãe precisa interromper a amamentação por meio de aleitamento materno, o copo educativo deve ser considerado a primeira opção para os bebês. Este copo deve ser um método utilizado temporariamente e de maneira alternativa à sucção do seio materno, pois no copo não se é feito movimentos de ordenha e nem sucção, o bebê apenas absorve o leite, no entanto a sucção do seio materno deve ser retomada assim que possível. ${ }^{19}$

\section{- Hábitos de Sucção Digital e Chupetas}

O hábito sem fim nutritivo mais frequente encontrado nas crianças é o da sucção digital, ao lado da sucção de chupetas, sendo prevalente nos primeiros anos de vida da criança e havendo uma diminuição desse hábito com o passar da idade. O dedo escolhido preferencialmente é o polegar, mas os outros dedos também estão associados. Esse tipo de sucção gera uma sensação prazerosa e satisfatória na criança e também satisfaz a necessidade nutritiva. ${ }^{20,21}$

Alguns autores relatam possíveis fatores que podem ser considerados causadores do uso da chupeta, como dificuldades, problemas e insegurança da mãe em amamentar seu bebê, conduta em relação a alguns profissionais quanto orientação inadequada sobre o uso da chupeta. A sucção da chupeta pode estar associada à pausa do aleitamento materno exclusivo, por conta da "confusão de bicos". ${ }^{22}$ Segundo Graber, ${ }^{23}$ até os 3 anos de idade hábitos de sucção dos dedos ou chupeta são uma maneira de suprir emocionalmente a criança e que não deve sofrer interferências, pois as alterações que são causadas nesse período da criança como, por exemplo, no segmento anterior dos arcos dentários, podem ser revertidas espontaneamente, assim que removidos esses hábitos de sucção.

A sucção digital promove diversas alterações na dentição, na musculatura peribucal e na oclusão. Da mesma forma, a sucção de chupeta apresenta alterações similares, no entanto o aspecto da mordida aberta anterior é mais circular. ${ }^{20,24}$ Embora essas alterações sejam semelhantes, sugere-se que por conta da dificuldade da paralisação da sucção de dedo, este hábito pode resultar em maiores efeitos deletérios. ${ }^{25}$ As alterações relatadas na literatura, como resposta a sucção digital persistente após os 4 anos de idade, são: retrognatismo mandibular, prognatismo maxilar, mordida aberta, musculatura labial superior hipotônica, musculatura labial inferior hipertônica, atresia do palato, interposição de língua, atresia do arco superior, respiração bucal, calo ósseo na região do polegar e assimetria anterior. ${ }^{26}$

\section{- Interposição da Língua e Deglutição Atípica}

A primeira função que surge no feto com 12 semanas é a deglutição, apresentando um processo complexo e integrado. As crianças portadoras de deglutição atípica apresentam lábios, língua, bochechas e músculos elevadores da mandíbula hipotônicos, apresentando as seguintes características: lábios evertidos, bochechas flácidas, mandíbula se mantém aberta e a língua apresenta um volume maior do que o normal. Há relatos na literatura que demonstram que as crian- 


\section{- Respiração Bucal}

A respiração por via nasal é considerada normal, entretanto, as crianças podem apresentar respiração bucal, a qual é causada por conta de obstrução das vias aéreas superiores ou, até mesmo, por um hábito, fazendo com que a passagem do ar seja feita pela boca. ${ }^{32}$ Podemos citar como etiologias da respiração bucal: hiperplasia adenomigdaliana, rinites alérgicas e não alérgicas e hipertrofia de cornetos inferiores. Dentre essas, a mais relacionada aos respiradores bucais é a rinite alérgica. ${ }^{33}$

Esta alteração da respiração modifica o padrão de crescimento da face, ocasionando também, em alguns casos, alterações morfofuncionais em todo o organismo. ${ }^{32}$ Segundo Aragão, ${ }^{34}$ as características faciais atípicas encontradas nas crianças respiradoras bucais são: boca entreaberta, lábio superior curto, lábio inferior volumoso e evertido, face estreita apresentando graus variáveis, nariz achatado, pequenos orifícios nasais e mal desenvolvidos. Além disso, quando há a instalação crônica da respiração bucal, na fase de desenvolvimento da criança, além de afetar o desenvolvimento facial normal, pode interferir também na saúde geral. ${ }^{35}$

\section{Discussão}

Os hábitos bucais deletérios têm sido um assunto de grande interesse, devido as suas consequências na oclusão e por estarem associados a características comportamentais das crianças. Dentro deste contexto, inúmeros estudos têm avaliado, especialmente, os hábitos de sucção e afirmam que, quando se diz respeito à diferença entre o aleitamento materno e a mamadeira, esta se apresenta no bico, pois o bico do seio materno se alonga e distende no interior da boca, enquanto os bicos das mamadeiras apresentam uma elasticidade inferior. ${ }^{14,36}$

Por outro lado, para Vinha et al., ${ }^{14}$ outras três diferenças podem também ser apontadas na literatura entre a sucção natural e a sucção artificial, como pega (posicionamento da língua e deglutição), a forma de extração do leite e a forma e elasticidade presentes nos bicos. Essas diferenças podem levar a introdução de novos hábitos e alterações oclusais, como já reportado previamente. ${ }^{16,37}$ Corroborando o estudo de Ferreira et al., ${ }^{37}$ Barreto et al., ${ }^{16}$ mostraram que crianças que foram aleitadas pelo seio materno, por um período de 6 meses ou mais, tem maior chance de não desenvolverem hábitos bucais deletérios, quando comparadas com crianças que tiveram um período de aleitamento materno inferior aos 6 meses. Neste sentido, é importante que a criança receba o aleitamento materno, não sendo a sucção por mamadeira, pois propiciará um aumento na possibilidade desta criança ser um respirador predominantemente nasal ao longo da vida. ${ }^{13}$

Por outro lado, autores mencionam que a alternativa mais fácil para a interrupção do aleitamento natural disponível é o aleitamento artificial. ${ }^{14,17} \mathrm{De}$ acordo com os autores, este aleitamento artificial iria saciar a necessidade do bebê e acalmar a ansiedade presente nos pais, solucionando, no entanto, os problemas de imediato, ${ }^{14}$ além do que o aleitamento através da mamadeira seria uma forma mais prática de nutrir o bebê. ${ }^{17}$

No entanto, para que o bebê faça a pega na mamadeira ele tem pouca necessidade de fazer uma abertura bucal, sendo que a forma dos bicos plásticos nas mamadeiras são constantes, fazendo com que a boca se enquadre no formato do bico. ${ }^{14}$ Assim, quando a sucção é feita pela mamadeira, a criança recebe uma pequena quantidade de estimulação motora-oral, gerando várias consequências como: flacidez dos músculos perioral e da língua, deformidade dos dentes e da face. ${ }^{13}$

Desta forma, Gomes et al. ${ }^{19}$ discordam quanto a alternativa de interrupção do aleitamento materno com o uso de mamadeiras, afirmando que essa interrupção deve ser feita por meio de um copo educativo, devendo ser um método utilizado temporariamente e de maneira alternativa, pois no copo não se é feito movimentos de ordenha e nem de sucção, sendo que o aleitamento materno deve ser retomado assim que possível quando ainda nos 6 primeiros meses do bebê.

Outros hábitos que podem ser instalados, durante a infância, especialmente, é o uso da chupeta ou sucção digital também considerados como hábitos de sucção, entretanto, não nutritivos. Alguns autores relatam possíveis fatores que podem ser considerados causadores do uso da chupeta, entre eles: dificuldades, problemas e insegurança da mãe em amamentar, conduta em relação a alguns profissionais quanto à orientação inadequada sobre o uso da chupeta, e associação à pausa do aleitamento materno exclusivo, por conta da "confusão de bicos". ${ }^{22}$ Além destes, o processo de sucção dos dedos e mãos ou de chupetas pode-se iniciar também devido à nutrição da criança ser realizada com o uso da mamadeira, pois sua necessidade fisiológica será satisfeita, porém sua necessidade natural de sucção não será suprida. ${ }^{20,38}$

Até os 3 anos de idade, os hábitos de sucção dos dedos ou da chupeta são uma forma de suprir emocionalmente a criança e que não deveria ser interferida, pois as alterações causadas nesse período, como exemplo no segmento anterior dos arcos dentários, podem ser revertidos espontaneamente, assim que removidos os hábitos de sucção. ${ }^{23}$ No entanto, estudos mais recentes sugerem que, por conta da dificuldade da paralisação da sucção de dedo, este hábito pode resultar em maiores efeitos deletérios e deveria ser removido o mais breve possível. ${ }^{25}$

As alterações relatadas na literatura por conta da sucção digital persistente após os 4 anos de idade são: retrognatismo mandibular, prognatismo maxilar, mordida aberta, musculatura labial superior hipotônica, musculatura labial inferior hipertônica, atresia do palato, interposição de língua, atresia do arco superior, respiração bucal, calo ósseo na região de polegar e assimetria anterior. ${ }^{26}$

Considerada como um hábito funcional, mas também deletério, as crianças portadoras de deglutição atípica apresentam lábios, língua, bochechas e músculos elevadores da mandíbula hipotônicos, apresentando as seguintes características: lábios evertidos, bochechas flácidas, mandíbula se mantém aberta e a língua apresenta um volume maior que o normal. ${ }^{27}$

Por outro lado, Fletcher et al. ${ }^{28}$ relatam ainda que os portadores de deglutição atípica apresentam ausência de con- 
tração do músculo masseter, dificuldade na deglutição quando o vedamento labial for impedido e protrusão da língua contra os dentes. Corroborando estes achados, estudos prévios também afirmam que a interposição lingual é uma consequência da deglutição atípica, podendo ser classificada como primária, quando esta é o fator principal para o desenvolvimento da má oclusão, ou secundária, quando a língua se adapta com uma alteração morfológica pré-existente em consequência à sucção de dedo ou chupeta..$^{20,24,30,39}$ Como resposta a essa interposição lingual, Silva Filho et al. ${ }^{30}$ observaram uma inclinação dos incisivos superiores e inferiores para a vestibular, fazendo com que haja um aumento do comprimento do arco dentário gerando um espaço entre os incisivos, ocasionando uma mordida aberta.

Neste contexto, os pacientes com respiração bucal, a qual pode estar associadoà presença de deglutição atípica, podem apresentar esse hábito funcional devido à hiperplasia adenomigdaliana, rinites alergias e não alérgicas e hipertrofia de cornetos inferiores. ${ }^{35}$ Esse hábito funcional modifica o padrão de crescimento da face, ocasionando também, em alguns casos, alterações morfofuncionais em todo o organismo. ${ }^{32}$ No entanto, quando há a instalação crônica da respiração bucal, na fase de desenvolvimento da criança, além de afetar o desenvolvimento facial normal, outros autores mencionam também a possível interferência na saúde geral. ${ }^{35}$

Dentro deste contexto, o que se percebe é que para essa remoção dos hábitos deve-se ter uma abordagem não somente feita pelos odontopediatras, mas também um controle psicológico, proporcionando a criança um atendimento multidisciplinar. ${ }^{40}$

\section{Conclusão}

É de extrema importância o aleitamento natural durante os seis primeiros meses de vida, diminuindo a chance de a criança desenvolver um hábito bucal deletério, sendo que o hábito mais frequentemente encontrado é o de sucção digital e/ ou chupeta. Quando instalados, esses hábitos podem levar a modificações no padrão de crescimento, desvios precocesno desenvolvimento do sistema estomatognático, se não houver uma correta estimulação das funções bucais, fazendo com que não se tenha um correto trabalho neuromuscular para a sucção, respiração e deglutição, levando a másoclusões. 
1- Pratik P,Desai VD. Prevalence of habits and oral mucosal lesions in Jaipur, Rajasthan. Indian J Dent Res. 2015;26(2):196-9.

2- Garde JB,Suryavanshi RK,Jawale BA,Deshmukh V,Dadhe DP,Suryavanshi MK. An epidemiological study to know the prevalence of deleterious oral habits among 6 to 12 year old children. J Int Oral Health. 2014;6(1):39-43.

3- Gonella S,Almeida M,Piovesan C,Andrade, A,Silveira C,Bonini G. Prevalência de Hábitos Bucais Deletérios em escolares da rede Estadual Boa Vista - RR. Arquivo Bras Odontol. 2012;8(2):1-7.

4- Mercadante MMN. Hábitos em ortodontia. In: Ferreira FV. Ortodontia: diagnóstico e planejamento clínico. 3. ed., São Paulo: Artes Médicas; 1999; p.253-79.

5- Serra-Negra JMC,Pordeus IA,Rocha Jr JF. Estudo da associação entre aleitamento, hábitos bucais e maloclusões. Rev. Odontol. Univ. São Paulo.1997;11(2):79-86

6- RosaGN,Del Fabro JP,Tomazoni F,Tuchtenhagen S,Alves, LS,Ardenghi TM. Association of malocclusion, happiness, and oral health-related quality of life (OHRQoL) in schoolchildren. J Public Health Dent. 2015; Jul 30.

7- Almeida RR,Santos SCB,Santos ECAS. Mordida aberta anterior - considerações e apresentação de um caso clínico. Rev Dental Press OrtodonOrtop Facial. 1998;3(2):17-29.

8- Galvão ACUR,Menezes SFL,Nemr K. Correlação de hábitos orais deletérios entre crianças de 4:00 a 6:00 anos de escola pública e escola particular da cidade de Manaus - AM. Revista CEFAC.2006;8(3):328-36.

9- Feres MF,Abreu LG,Insabralde NM,De Almeida MR,Flores-Mir C. Effectiveness of open bite correction when managing deleterious oral habits in growing children and adolescents: a systematic review and meta-analysis. Eur J Orthod. 2016;3.

10- Marchesan IQ.Motrocidade Oral - Visão clínica do trabalho fonoaudiólogo integrado com outras especialidades. São Paulo: Editora Pancast, 1993. 11- Correa MSNP. Odontopediatria na primeira infância. $2^{\text {a }}$ reimpressão. São Paulo: Santos, 2001

12- Gellin ME. Digital sucking and tongue thrusting in children. Dent Clin North AM. 1978;22(4):603-19.

13- Neiva FCB,Cattoni DM,Ramos JLA,Issler H. Desmame precoce: implicações para o desenvolvimento motor-oral. JPediatr. 2003;79(1):7-12.

14- Vinha PP. et al. Alterações morfofuncionais decorrentes do uso da mamadeira. In: Issler H. O aleitamento materno no contexto atual - políticas, práticas e bases científicas. Ed. Sarvier, 2008, p.444-61.

15- Franç MCT,Giugliane ERJ,Oliveira LD,Weigert EML,Santo LCE,Köhler $\mathrm{CV}$, et al. Uso de mamadeira no primeiro mês de vida: determinantes e influência na técnica de amamentação. Rev Saúde Pública.2008;42(4):607-14.

16- Barreto EPR,Faria MMG,Castro PRS. Hábitos bucais de sucção não nutritiva, dedo e chupeta: abordagem multidisciplinar. J BrasOdontopediatr Odontol. Bebê.2008;66(29):42-8.

17- Eny EM,Nascimento MJP. Causas e consequências do desmame precoce: uma abordagem histórico-cultural. RevEnfermUnisa. 2001;2:52-6.

18- Paglia, L. Does breastfeeding increase risk of early childhood caries? Eur J Paediatr Dent. 2015;16(3):173.

19- Gomes CF,Trezza EMC,Murade ECM,Padovani CR. Avaliação eletromiográfica com eletrodos de captação de superfície dos músculos masseter, temporal e bucinador de lactentes em situação de aleitamento natural e artificial. J Pediatr. 2006;82(2):103-9.

20- Silva Filho OG,Okada T,Santos SD. Sucção digital: abordagem multidisciplinar: ortodontia x psicologia x fonoaudiologia. Estomat. Cult. 1986;16(2):38-44.

21- Valdrighi HC,Vedovello Filho M,Coser RM,Paula DB,Rezende SE. Hábitos Deletérios x Aleitamento Materno (Sucção Digital ou Chupeta). RGO.2009;52(4):237-9.

22- Cotrim LC,Venancio SI,Escuder MML. Uso de chupeta e amamentação em crianças menores de quatro meses no estado de São Paulo. RevBras Saúde Mater Infant. 2002;2(3):245-52

23- Graber TM. Orthodontic Principles and practice. 2. Ed.Filadelfia: W.B. Saunders Company, 1966.

24- Almeida RR,Ursi WJ. Anterior open bite. Etiology and treatment. Oral Health. 1990;80(1):27-31.

25- Queluz DP,Gimenez CMM. Aleitamento e hábitos deletérios relacionados à oclusão. Rev Paul Odontol2000;17(6):16-20.

26- Moresca CA,FeresNA. Hábitos Viciosos Bucais. In: Petrelli, E. Ortodontia Para Fonoaudiologia. Curitiba: Editora Lovise, 1994.

27- Altmann EBC. Fisioterapia, fonoaudiologia e terapia ocupacional em pediatria. São Paulo: Sorvier, 1990.

28- Fletcher SG,Casteel RL,Bradley DP. Tongue-thrust swallow, speech articulation, and age. J Speech Hear Disord. 1961;26(3):201-8.

29- Vieira Filho JG,Ourique SAM. Deglutição atípica e as desordens craniomandibulares. J Bras ATM Ocl Dor Orofacial.2000;1(2):142-6.

30- Da Silva Filho OG,Gomes Gonçalves RJ,Maia FA. Sucking habits: clinical managements in dentistry. JClinPediatDent.1991;15(3):137-56.

31- Sharma S,Bansal A,Asopa K. Prevalence of Oral Habits among Eleven to Thirteen Years Old Children in Jaipur. Int J Clin. Pediatr Dent. 2015;8(3):208-10.

32- Bianchini AP,Guedes ZCF,Vieira MM. Estudo da relação entre a respiração oral e o tipo facial. Rev. Bras. Otorrinolaringol. 2007;73(4):500-5.

33- Di Francesco RC. Respiração bucal. A visão do otorrinolaringologista. J Bras Ortodontia Ortop. Facial 1999;4(21):241-7.

34- Aragão W. Respirador bucal. J Pediatr. 1998;64(8):349-52.

35- Motonaga SM,Berte LC,Anselmo-Lima WT. Respiração bucal: causas e alterações no sistema estomatognático. RevBrasOtorrinolaringol. 2000;66(4):373-9.

36- Nowak AJ,Smith WL,ErenbergA. Imaging evaluation of breast-feeding and bottle-feeding systems. J Pediatr. 1995;126(6):S130-4.

37- Ferreira FV,Marchionatti AM,Oliveira MDM,Praetzel JR. Associação entre a duração do aleitamento materno e sua influência sobre o desenvolvimento de hábitos orais deletérios. Rev Sul-Bras Odontol.2010;7(1):35-40. 38- Estripeaut LE,Henriques JFC, Almeida RR. Hábito de sucção de polegar e má oclusão - Apresentação de um caso clínico. RevOdont USP. 1989;3(2):371-6.

39- Silva Filho OG,Chaves ASM,Almeida RR. Efeitos terapêuticos suscitados pelo uso da grade palatina: um estudo cefalométrico. RevSocParanOrtod. 1996;1(1):9-15.

40- Silva EL. Hábitos bucais deletérios. Rev Para Med.2006;20(2):47-50.

Recebido em: 12/03/2016 Aprovado em: 28/03/2016

\section{Tamara Kerber Tedesco}

Av. Dr. Maximiliano Baruto, 500 - Jd. Universitário

Araras/SP, Brasil - CEP:13607-338

E-mail: tamarakt@usp.br 